\title{
Danzas tradicionales del pueblo ulwa en la comunidad indígena de Karawala \\ Orlando Santiago Martínez
}

La cultura del pueblo indígena ulwa forma parte del acervo cultural indígena de Nicaragua. En Karawala habita la mayor comunidad ulwa en la Región Autónoma Atlántico Sur. Son pocas las personas que conocen la historia de las diferentes danzas tradicionales del pueblo indígena ulwa. Gracias al Programa Conjunto de Revitalización Cultural y Desarrollo Productivo Creativo en la Costa Caribe de Nicaragua y a la memoria histórica de los portadores culturales de la comunidad, es que ha sido posible documentar y presentar, a los lectores de Wani, las danzas y sus significados para el pueblo ulwa y, específicamente, para la comunidad indígena de Karawala, municipio de la Desembocadura de Río Grande.

Esperamos que esta investigación sirva a las distintas instancias del Municipio, sobre todo al Ministerio de Educación (MINED), como material didáctico de enseñanza en las materias que tienen que ver con el arte y la cultura, y que se imparten en los centros educativos de primaria y de secundaria. En las alcaldías y casas comunales de la Desembocadura de Rio Grande, también servirá como un documento de información sobre la cultura artística de las danzas tradicionales del pueblo Ulwa de Karawala. De esta forma, los estudiantes, los ulwas y la población en general (nacionales e internacionales) podrán obtener información sobre este importante aspecto de la cultura tradicional ulwa.

Históricamente, los pobladores del pueblo indígena de Karawala han hecho de las danzas una actividad culturalmente importante. En la actualidad, con la incorporación de otras culturas ha venido disminuyendo el valor de las danzas tradicionales en la comunidad. Es necesario revitalizar este aspecto de la cultura ulwa, en vista de que Karawala es un destino turístico.

Estas danzas son de gran importancia para la comunidad, pues los conecta con su historia, la naturaleza y sus ancestros, y porque son parte del patrimonio cultural intangible del pueblo ulwa. Karawala alberga una rica historia acerca de los primeros ulwas que habitaron la costa caribe de Nicaragua. En ese sentido, el tema de una de las principales danzas tradicionales el Awawak es la fundación de la comunidad. De tal manera que se conserva en la comunidad, como un patrimonio de la historia ulwa.

Estas danzas son potencialmente fuente de atracción turística, con lo cual podría beneficiarse la comunidad. En el Awawak, por ejemplo, se baila con trajes coloridos $\mathrm{y}$ de muchos movimientos que imitan la naturaleza. Atrae a muchos turistas nacionales y extranjeros. En vista de que Karawala es un destino, turístico, los pobladores de la comunidad consideran de mucha importancia conservar y enseñar las danzas tradicionales a jóvenes ulwas, para mantener viva la cultura danzante de los ulwas de Karawala. Esto con la finalidad de atraer turistas, promover las artes escénicas tradicionales, la gastronomía y también la gastronomía y artesanía ulwas..

\section{ORIGEN DE LAS DANZAS ULWAS}

La conservación de la historia y la celebración de las danzas ulwas se debe, en parte, a un grupo de ancianos llamado Uyutmubal. Éstos ancianos forman parte de la comunidad y han emprendido el esfuerzo de dar a conocer las historias ulwas, entre ellas, las danzas, las cuales son netamente originales del pueblo Ulwa y no son relatadas por ningún otro pueblo indígena ni son adaptadas de otras culturas indígenas de la zona.

Los ancianos portadores culturales del grupo focal cuentan que el origen de estas danzas tradicionales fue un pájaro llamado "tiwilis" por los ancestros ulwas originarios de la zona. Estas aves viven en la orilla de los caños y ríos. Tienen sus meses de aparición en noviembre y diciembre, tiempo en que los ancestros ulwas observaban sus rítmicos 
movimientos que luego imitaron danzando. De allí la razón por la cual el grupo de danza tradicional conformado por jóvenes estudiantes ulwas lleva el nombre de "Los Tiwilis de Karawala".

\section{DESCRIPCIÓN DE LAS DANZAS ULWAS}

Las danzas de las cuales hablaremos a continuación son seis: Awawak, Watiu, Ukung, Nahsirau, Wasbulu, Saudah. Todas ellas tienen grandes significados para el pueblo ulwa.

\section{La danza del Awawak}

Esta danza representa el inicio de la comunidad ulwa en Karawala, al punto que Awawak significa Karawala en ulwa. Se realiza una vez al año el seis de mayo, fecha del aniversario de la comunidad de Karawala.

Los participantes son siete varones ancianos que representan los siete fundadores. Cada uno de los participantes lleva una vestimenta diferente, muy atractiva y de muchos colores. Uno de ellos se viste de piel de tigre; otro, con tejidos de bejucos; el tercero, con taparrabo de hojas de palma; el cuarto, con cáscaras de corteza de árbol; el quinto, con vestimenta completa de hoja de palma; otro, con plumas de aves, y el ultimo completamente cubierto de barro. Cada una de estas vestimentas lleva el nombre de los primeros fundadores de Karawala.

Los movimientos de esta danza son al ritmo de la naturaleza de su vestimenta. Por ejemplo, el participante con la vestimenta de piel de tigre hace movimientos y rugidos que representan a este animal (tigre).

Esta danza tiene una duración de diez a quince minutos y termina cuando el último de los siete participantes hace su representación de la naturaleza de su vestimenta.

\section{La danza Watiu}

Esta danza tiene relación con la vida en la naturaleza. Es dedicada a las plantas medicinales de la zona. El Watiu es el gran (medico curandero) dentro del grupo ulwa.

En esta danza, los integrantes se visten a semejanza de la naturaleza (palmas de coco, entre otras hojas de palmeras). La época del año para esta danza es el verano, pues es la época donde las plantas medicinales se mueren por falta lluvia y los ancianos le dedican esta danza a la naturaleza para que mantenga vivas estas plantas que son esenciales para la salud.

El Watiu lo danzan solamente los ancianos y ancianas de la comunidad ulwa. Son ocho los participantes: cuatro hombres y cuatro mujeres. No lleva música, pero si un ritmo compuesto de sonidos que son imitaciones de la naturaleza (la lluvia, el viento, los truenos). Las voces de cada integrante se juntan y forman el ritmo con las voces de la naturaleza. Esto es lo que da vida a esta danza.

Los movimientos de la danza del Watiu son de pasos grandes, moviendo las manos y cabezas. Al iniciar la danza, los ocho integrantes forman un círculo, luego se dividen en parejas de mujer y varón, realizando sus respectivos roles de la naturaleza (viento, truenos, lluvia, etcétera). Para finalizar la danza, el Watiu (médico, sukia o curandero) ordena la separación de las parejas manteniendo los movimientos de los pasos grandes y la cabeza hasta desaparecer del público.

\section{La danza Ukung}

Esta danza es un símbolo del trabajo doméstico de las mujeres ulwas, las cuales llevan palmas en representación de su trabajo en el hogar, y de los hombres como proveedores del hogar. Éstos se presentan con lanzas como símbolo de la caza y la pesca.

Los integrantes de esta danza son ocho jóvenes ulwas: cuatro varones y cuatro mujeres, todos entre los dieciocho y veinte años. En esta danza, los integrantes se mueven al ritmo lento de una música tradicional ulwa. Ésta es producida por dos tambores llamados $s u$ en lengua ulwa y dos conchas de tortuga de río llamadas kwaah ukatak. La danza tiene una duración de ocho minutos, que representa la jornada de ocho horas en el hogar para la mujer; y en el campo o en el rio, para el hombre.

La vestimenta es de piel de venado. Los varones se ornamentan con lanzas y arcos, en representación del éxito de la caza, y las mujeres se visten con hojas de palmeras y llevan escobas de palma en las manos, como signo de su labor doméstica.

Esta danza comienza con una presentación, de los cuatro varones. Luego se presentan las cuatro jóvenes mujeres. Después de estas presentaciones, las mujeres toman una posición en cada esquina del escenario. En este momento comienza la música de los tambores y concha de tortuga de río, las mujeres comienzan el movimiento de sacudir 
con sus escobas de palma, en representación de trabajo domestico. Todos estos movimientos de las mujeres, se hacen al ritmo de los tambores. Al mismo tiempo, los varones realizan movimientos que representan trabajos en el campo (caza, pesca, etcétera). La danza se realiza de esta manera hasta que los hombres en representación del éxito de la caza y pesca regresan al hogar y festejan con toda la comunidad el éxito y la buena fortuna.

\section{La danza Nahsirau}

Esta danza representa la fertilidad de la mujer y el rito sobre el cortejo de los jóvenes en la comunidad ulwa. Está integrada por cinco participantes: cuatro jóvenes mujeres, entre las edades de doce a dieciséis años, y un varón de doce a dieciséis años. En esta danza, los integrantes se mueven al ritmo de la música tradicional ulwa, con un tempo rápido de tambores y conchas de tortuga de río.

Al inicio de esta danza, las cuatro jóvenes mujeres inician con interpretaciones de actividades del hogar, usando movimientos rítmicos al tempo de la música de los tambores (lavando cocinado barriendo y vistiéndose para salir). Todo esto con la intención de atraer la atención del único varón disponible. La danza termina al momento que el varón escoge una de las cuatro jóvenes para ser su pareja de danza el chula significa la aceptación del cortejo de esta pareja joven dentro de la comunidad Ulwa.

\section{La danza Wasbulu}

El Wasbulu representa la cosecha de las frutas del año en la comunidad. Es también la bebida tradicional ulwa. En esta danza participan mujeres y varones de todas las edades. Es una danza de participación libre para toda la comunidad.

El Wasbulu se danza al aire libre, alrededor de varias fogatas y al ritmo de la música tradicional ulwa con tambores $(s u)$ y las conchas de tortuga (kwaah ukatak). Los ritmos pueden ser suaves o rápidos y los danzantes son toda la comunidad. En el momento de la danza a los participantes se les da jugos de frutas fermentadas para beber y también para dar de ofrenda al dios de la cosecha.

\section{La danza Saudah}

Esta danza representa la práctica de la agricultura en la comunidad ulwa. En el pasado, los participantes de esta danza eran toda la comunidad que se reunían alrededor de las tierras recientemente cultivadas, para festejar la finalización de las siembras con comida bebidas y cantos, gritos y tonos de alegría.

En la actualidad, los participantes de esta danza son los ancianos de la comunidad. Los grupos están integrados por 16 personas: 12 mujeres y cuatro varones. Los movimientos de esta danza son acompasados por los sonidos de la naturaleza imitados rítmicamente por los participantes de la danza. Tiene una duración de quince a veinte minutos en los cuales los participantes hacen una imitación de comer, beber y danzar alrededor de las tierras recientemente cultivadas, en un ambiente lleno de alegría por la finalización de la siembra.

\section{RECOMENDACIONES}

Coordinar con el ministerio de educación de la región, para la inclusión de esta investigación como material didáctico de cultura tradicional, en los centros educativos de Karawala.

Apoyo en la promoción de revitalización cultural de grupos de danzas artísticas tradicionales de jóvenes ulwas de Karawala, por parte de la Secretaria de Cultura del Consejo Regional de la RAAAS.

Se recomienda que el gobierno comunal y gobierno municipal de Karawala promuevan las fiestas artísticas tradicionales ulwas, a nivel regional, nacional e internacional, para atraer turistas a la comunidad.

\section{PORTADORES CULTURALES COMUNITARIOS}

Morphy Salazar, Ana Palmiston Briton, Kenia Wilson Escobar, Chester Lam Palmiston 